\title{
Familial Sarcoidosis: An Analysis of Twenty-Eight Cases
}

\author{
Dildar Duman ${ }^{1}$, Tülin Sevim ${ }^{1}$ Lale Sertçelik ${ }^{1}$, Olga Akkan¹, Sinem Güngör ${ }^{1}$,

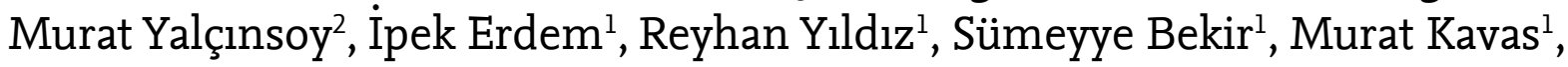 \\ Armağan Hazar ${ }^{1}$, Esen Akkaya ${ }^{1}$
}

${ }^{1}$ Department of Pulmonology, Süreyyapaşa Chest Diseases and Thoracic Surgery Trainig and Research Hospital, İstanbul, Turkey ${ }^{2}$ Department of Pulmonology, Inönü University School of Medicine, Malatya, Turkey

\begin{abstract}
Objective: Sarcoidosis is a multisystemic disease, exact cause of disease is unknown but it is assumed that genetic predisposition and ethnic factors play a role in etiology. Studies related with familial sarcoidosis is limited and only case reports about familial sarcoidosis is available from our country. We aimed to evaluate the prevelance of familial sarcoidosis and clinical findings of cases with familial sarcoidosis.
\end{abstract}

Methods: We retrospectively documented file records of 678 patients diagnosed with sarcoidosis and followed up in outpatient clinic of sarcoidosis from January 1996 to February 2016. 28 familial sarcoidosis cases in 14 families were enrolled into the study. Their demographic findings, family relationship, symptoms, laboratory and pulmonary function test results, radiological apperances, diagnostic methods, treatments were recorded.

Results: Twenty-eight sarcoidosis patients out of 678 reported as familial cases, giving a prevelance of familial sarcoidosis as $4 \%$. There were 8 sarcoidosis sib, 4 sarcoidosis mother-child, 1 sarcoidosis father-child and 1 sarcoidosis cousin relationship. Female/male ratio was 1.8 , mean age of the study population was 43 , most freguent symptoms were cough and dyspnea, stage 2 was mostly seen according to chest $\mathrm{X}$-ray, most common CT appearance was mediastinal lymphadenopathy and mediastinoscopy was the most freguent diagnostic method.

Conclusion: This study is important to lead interrogation of family in patients with suspected sarcoidosis and future studies investigating familial aggregation in sarcoidosis.

Keywords: Familial, mediastinoscopy, sarcoidosis

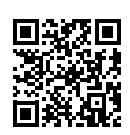

Received Date: 15.03 .2016 Accepted Date: 22.07 .2016

DOI: 10.5152/ejp.2016.28863

Corresponding Author

Dildar Duman

E-mail: dildaryetis@yahoo.com

-Available online at www.eurasianjpulmonol.com

This work is licensed under a Creative Commons Attribution-NonCommercial 4.0 International License.

\section{INTRODUCTION}

Sarcoidosis is a multisystemic disease with unknown etiology; it is histologically characterized by non-caseating granulomas (1). Ethnic factors and genetics are thought to play a role in the etiology of the disease $(2,3)$. Although familial predisposition is known in sarcoidosis, its inheritance pattern has not yet been defined. In African-Americans, familial history appears to be an especially common risk factor for sarcoidosis (4). The first familial sarcoidosis case worldwide was identified in two sisters in Germany in 1923 (5). The prevalence of familial sarcoidosis has been reported to be $4.3 \%$ in Japan, $4.7 \%$ in Finland, $5.9 \%$ in the USA, and $17 \%$ in African-Americans $(6,7)$.

In a study on the epidemiological features of sarcoidosis patients in Turkey, three of 293 patients were reported to have sarcoidosis cases in their families; this rate was revealed to be $1 \%$ in another study on sarcoidosis $(8,9)$. However, no studies have been published on patients with familial sarcoidosis. Instead, this disease has been presented as case reports. Therefore, in this retrospective study, we aimed to investigate the prevalence of familial sarcoidosis and the features of cases with familial sarcoidosis that were followed up in the outpatient sarcoidosis clinic of our hospital.

\section{METHODS}

This retrospective study was conducted at Süreyyapaşa Chest Diseases and Thoracic Surgery Training and Research Hospital after receiving approval from the Ethics Committee of the hospital. The files of 
678 patients followed up due to a diagnosis of sarcoidosis in the outpatient sarcoidosis clinic between January 1996 and February 2016 were retrospectively examined. Based on the recordings in their files, 28 patients with a familial history of sarcoidosis were included in the study.

Diagnostic criteria for sarcoidosis were as follows:

- Detection of non-caseating granuloma in biopsy samples taken from the lungs or extrapulmonary organs, elimination of other diseases causing granulomatous inflammation, and consistency of patient's clinical and radiological findings with sarcoidosis.

- Presence of other organ involvement, including the skin in cases where skin biopsy revealed granulomatous inflammation.

- Cases with clinical and radiological findings consistent with sarcoidosis but who could not undergo biopsy or refused to undergo biopsy; if the patient's bronchoalveolar lavage (BAL) fluid was lymphocytic, CD4/CD8 was higher than 3.5, and clinical course was consistent, the patient was diagnosed with sarcoidosis.

The patients were staged according to their chest radiography findings (1). Stage 0 was evaluated as normal posteroanterior (PA) chest radiography, stage I as bilateral hilar lymphadenopathy, stage II as parenchymal infiltration with bilateral hilar adenopathy, stage III as parenchymal infiltration without hilar lymphadenopathy, and stage IV as pulmonary fibrosis.

Data on the patients' ages, genders, degrees of affinity, symptoms, physical examination findings, stage of disease according to chest radiography, findings of thoracic tomography, respiratory function test (RFT), carbon monoxide diffusion capacity (DLCO) values, serum angiotensin converting enzyme (ACE) and calcium values, and diagnostic techniques used for diagnosing sarcoidosis, extrapulmonary organ involvement, and applied treatments were obtained from their files.

\section{RESULTS}

Of 678 patients who were followed up because of a diagnosis of sarcoidosis, 28 had familial sarcoidosis. The prevalence of familial sarcoidosis was found to be $4 \%$. All familial sarcoidosis cases are presented in Table 1. Eighteen patients were female and 10 were male. The female/male ratio was 1.8. The diagnostic age range for sarcoidosis was $26-73$ years, and the mean age was $43 \pm 12$ years. Familial sarcoidosis was mostly observed among siblings. There was a sibling-sibling relationship in eight families, a mother-child relationship in four families, a father-child relationship in one family, and a cousin-cousin relationship in one family (Table 2). Only five of 28 patients smoked (17\%). The most common complaints with which patients presented were cough (53\%), shortness of breath (53\%), and chest pain (39\%). The most common extrapulmonary symptom was fatigue (25\%) (Table 3$)$.

Skin sarcoidosis was the most frequently observed extrapulmonary organ involvement; it was found in five patients (17\%). In one case, the involvement of sarcoidosis was observed as skin lesions in the nose and elbow. In half of the patients, the ACE value was found to be high; the mean ACE level in all patients was $66.9 \mathrm{U} / \mathrm{L}$ (normal intervals: $8-52$ ). The results of respiratory function tests were normal in $32 \%$ of familial sarcoidosis cases. Regarding respiratory functions, $67 \%$ of the
Table 1. The relationships between age, gender, and familial sarcoidosis in patients with sarcoidosis

\begin{tabular}{|c|c|c|c|c|}
\hline Family & Case & Gender & Age & Relationship \\
\hline 1 & 1 & $\mathrm{~F}$ & 62 & Mother \\
\hline 1 & 2 & $M$ & 40 & Son \\
\hline 2 & 3 & $M$ & 42 & Father \\
\hline 2 & 4 & $M$ & 28 & Son \\
\hline 3 & 5 & $\mathrm{~F}$ & 37 & Cousin \\
\hline 3 & 6 & $\mathrm{~F}$ & 50 & Cousin \\
\hline 4 & 7 & $\mathrm{~F}$ & 53 & Mother \\
\hline 4 & 8 & $\mathrm{~F}$ & 32 & Daughter \\
\hline 5 & 9 & $\mathrm{~F}$ & 45 & Sibling \\
\hline 5 & 10 & $M$ & 33 & Sibling \\
\hline 6 & 11 & $\mathrm{~F}$ & 73 & Mother \\
\hline 6 & 12 & $\mathrm{~F}$ & 52 & Daughter \\
\hline 7 & 13 & $M$ & 52 & Sibling \\
\hline 7 & 14 & $M$ & 45 & Sibling \\
\hline 8 & 15 & $\mathrm{~F}$ & 67 & Mother \\
\hline 8 & 16 & $\mathrm{~F}$ & 46 & Daughter \\
\hline 9 & 17 & $M$ & 30 & Sibling \\
\hline 9 & 18 & $\mathrm{~F}$ & 38 & Sibling \\
\hline 10 & 19 & $\mathrm{~F}$ & 67 & Sibling \\
\hline 10 & 20 & $\mathrm{~F}$ & 51 & Sibling \\
\hline 11 & 21 & $\mathrm{~F}$ & 29 & Sibling \\
\hline 11 & 22 & $\mathrm{~F}$ & 28 & Sibling \\
\hline 12 & 23 & $\mathrm{~F}$ & 47 & Sibling \\
\hline 12 & 24 & $\mathrm{~F}$ & 44 & Sibling \\
\hline 13 & 25 & $M$ & 26 & Sibling \\
\hline 13 & 26 & $M$ & 30 & Sibling \\
\hline 14 & 27 & $F$ & 43 & Sibling \\
\hline 14 & 28 & $M$ & 32 & Sibling \\
\hline
\end{tabular}

F: Female; M: male

Table 2. Demographic and familial features of patients with sarcoidosis

\begin{tabular}{|l|c|c|}
\hline Gender: female/male ratio & $18 / 10$ & \\
Age & $43.6 \pm 12(26-73)$ & \\
Familial relationship & $\mathrm{n}$ & $\%$ \\
\hline Sibling-sibling & 8 & 28 \\
Mother-child & 4 & 14 \\
Father-child & 1 & 3 \\
Cousin-cousin & 1 & 3 \\
\hline
\end{tabular}


Table 3. Distribution of patients according to complaints

\begin{tabular}{|l|c|c|}
\hline Complaint & $\mathbf{n}$ & $\%$ \\
\hline Cough & 15 & 53 \\
Shortness of breath & 15 & 53 \\
Chest pain & 11 & 39 \\
Malaise-fatigue & 7 & 25 \\
Weight loss & 4 & 14 \\
\hline Fever & 1 & 3 \\
Night sweats & 1 & 3 \\
\hline
\end{tabular}

Table 4. Staging of patients according to chest radiography

\begin{tabular}{|l|c|c|}
\hline Stage & $\mathbf{n}$ & $\%$ \\
\hline Stage 0 & - & 0 \\
\hline Stage I & 10 & 35 \\
\hline Stage II & 15 & 53 \\
Stage III & 2 & 7 \\
\hline Stage IV & 1 & 3 \\
\hline
\end{tabular}

Table 5. Frequency of thoracic CT findings in patients

\begin{tabular}{|l|c|c|}
\hline & $\mathbf{n}$ & \\
\hline Mediastinal enlarged lymph nodes & 25 & 89 \\
Nodules & 13 & 46 \\
Reticular infiltration & 11 & 39 \\
Ground glass appearance & 5 & 17 \\
Bronchiectasis & 2 & 7 \\
Honeycomb & 2 & 7 \\
Diffuse fibrosis & 1 & 3 \\
Cavity & 1 & 3 \\
\hline
\end{tabular}

Table 6. Diagnostic techniques used for patients

\begin{tabular}{|l|c|c|}
\hline & $\mathbf{n}$ & $\%$ \\
\hline Mediastinoscopy & 17 & 60 \\
\hline Transbronchial biopsy & 4 & 14 \\
Mucosal biopsy & 3 & 10 \\
\hline Transbronchial needle aspiration & 1 & 3 \\
Open lung biopsy & 1 & 3 \\
\hline Clinical radiological & 1 & 3 \\
\hline
\end{tabular}

patients had pathologies and 35\% had restrictive patterns. The mean percentage of DLCO value was detected to be $81 \%$. When staging the disease according to PA radiography, the most common stage was stage II. Ten cases were stage I, 15 cases were stage II, two cases were stage III, and one case was stage IV (Table 4). The most frequent thoracic tomography finding was mediastinal lymphadenopathy $(89 \%)$. This was followed by nodules (46\%) and reticular infiltration (39\%). The thoracic CT findings are shown in Table 5 . In total, $75 \%$ of the patients underwent bronchoscopy. In $28 \%$ of the patients who underwent bronchoscopy, a normal endobronchial system was observed. Pathologically, the most common finding was mucosal hyperemia (42\%). Other less frequent findings were mucosal infiltration (23\%), nodular lesion (19\%), and external bronchial compression (14\%). Seven of nine patients undergoing BAL were found to be lymphocytic. Non-caseating granulomas were revealed through transbronchial biopsy in three cases, transbronchial needle aspiration biopsy in one case, and mucosa biopsy in one case. Non-caseating granulomas were observed using skin biopsy in four cases and lung biopsy in one case. The diagnosis of sarcoidosis was established through mediastinoscopy in 17 patients (60\%). A patient who refused to undergo further diagnostic tests was diagnosed with clinical-radiological sarcoidosis. With the exception of this case, histopathological diagnosis was obtained in all cases. The diagnostic techniques used in the cases are summarized in Table 6.

\section{DISCUSSION}

In our country, no original research study has been performed on patients with familial sarcoidosis. Instead, this disease has been presented as case reports. In our study, which is the first research study to be conducted on familial sarcoidosis in our country, the frequency of familial sarcoidosis was found to be $4 \%$. This rate is quite high compared with those reported in studies performed in our countries. This may be due to the fact that our patients were questioned about the presence of sarcoidosis in their families and patients having complaints that were consistent with sarcoidosis were scanned. In our study, the importance of scanning familial history of sarcoidosis was emphasized.

In a study performed on 1,082 patients with sarcoidosis in America, the prevalence of familial sarcoidosis was found to be $14 \%$; the prevalence was three times higher among African-Americans than among Caucasians (10). This rate was reported to be between $3.6 \%$ and $4.7 \%$ in Finland and between $2.9 \%$ and $4.3 \%$ in Japan (11). The incidence of familial sarcoidosis was found to be $3 \%$ in the ACCESS study and $5.9 \%$ in a study by McGrath et al. $(7,12)$. In a multi-center study on sarcoidosis in Turkey, the frequency of familial sarcoidosis was revealed to be $1 \%$. This rate was found to be $3 \%$ in a study conducted by Aykan et al. $(9,13)$. Among 678 sarcoidosis cases followed in our study, there were 28 familial sarcoidosis cases, with a prevalence of $4 \%$. This rate is higher than the rate previously reported in our country but is consistent with the literature.

Familial sarcoidosis is mostly seen in siblings, then in mother-child relationships, and less frequently in father-child relationships (11, 12). Its prevalence is high in monozygotic twins and in the same race, which suggests that the disease has a genetic component $(10,14)$. In our country, several series were defined as familial sarcoidosis cases. A case of two sisters was reported in a study by Yavşan et al. (15), and a father-son case was presented in a study by Uyar et al. (16). Consistent with the literature, sarcoidosis was mostly observed in siblings and then in mother-child relationships in our study. There were eight sibling-sibling, three mother-daughter, one mother-son, one father-son, and one cousin-cousin sarcoidosis cases in the study. 
Considering that the etiology of sarcoidosis includes ethnic factors and genetic predisposition, HLA (human leukocyte antigen) genes have been a focus of study. Uyar et al. (16) reported common HLA DPB1, HLA DQB1, HLA DRB1, and HLA DRB5 alleles in the HLA gene analysis of familial sarcoidosis cases. On the other hand, Yavşan et al. (15) found common HLA 24, B 51, Cw 07, DRB1 15, and DQB1 06 alleles. In our study, HLA gene analysis could not be performed.

No difference was found between familial sarcoidosis and non-familial sarcoidosis with regard to clinical presentation and prognosis (11, 17). Sarcoidosis is a disease that is often seen in young adolescents and women (18). While the male/female ratio is 1.77 in the ACCESS study, it was found to be 3.1, 2.08, and 2.8 in sarcoidosis studies performed in Turkey $(9,13,18,19)$. The mean age was found to be 43 years for our patients with familial sarcoidosis at the time of diagnosis. The female/male ratio was 1.8 . Sarcoidosis was reported to be more frequent among non-smokers, and there was a negative correlation between smoking and sarcoidosis. In two studies, $8 \%$ and $20 \%$ of patients with sarcoidosis were active smokers $(9,13)$. In our study, only five of 28 patients with familial sarcoidosis smoked; the rate was calculated to be $17 \%$.

The most common symptoms of sarcoidosis are cough, shortness of breath, and chest pain $(9,13)$. Moreover, patients with familial sarcoidosis mostly presented with complaints of cough (53\%), shortness of breath (53\%), and chest pain (39\%). The most frequent extrapulmonary symptom was fatigue (25\%). The most common extrapulmonary organ involvement was reported to be skin sarcoidosis (32\%) in the study by Aykan et al. (9). In contrast, the rate of skin sarcoidosis was $15 \%$ in the study by lç̧ten et al. (20). Skin sarcoidosis was found to be the most common extrapulmonary organ involvement in cases with familial sarcoidosis in our study; it was defined in $17 \%$ of the cases.

In sarcoidosis patients, high ACE levels have been reported at rates of $56 \%$ and $61 \%(9,13,19)$. ACE levels were also high in half of our patients with familial sarcoidosis.

Various rates have been reported for the most common functional disorders in sarcoidosis. When progressing from stage 1 to stage 4 , $\mathrm{FEV}_{1}$ and DLCO values are expected to decrease (19). While restrictive disorder was reported to be more common in the ACCESS study (30\%), no pathology was found in the respiratory functions of $60 \%$ of patients in the study by Baran et al. $(12,19)$. While respiratory function tests were normal in $32 \%$ of cases with familial sarcoidosis, restrictive patterns were observed in $35 \%$ of patients in our study. The mean DLCO percentage was detected to be $81 \%$.

In our study, when the disease was staged according to the results of chest radiography, the cases were mostly in stage 1 and 2 (35\% in stage 1 and 53\% in stage 2). In other studies on sarcoidosis in Turkey, patients were reported to be in stage 1 at rates between $35 \%$ and $44 \%$ and in stage 2 at rates between $40 \%$ and $43 \%(9,19)$. Similar to previous studies on sarcoidosis $(13,19)$, thoracic tomography in our study revealed the most frequent pathologies to be mediastinal lymphadenopathy, nodules, and reticular appearance.

Non-caseating granulomas must generally be demonstrated histopathologically for the diagnosis of sarcoidosis $(1,21)$. The method of biopsy can differ according to the organ that is involved, patient performance, available techniques, and experience of the physician (13). In our study, except for one patient who had findings clinically and radiologically consistent with sarcoidosis but rejected advanced examination, non-caseating granulomas were histopathologically defined in all cases with familial sarcoidosis.

Bronchoscopy is a safe and minimally invasive method for the diagnosis of sarcoidosis. Moreover, it enables BAL, transbronchial needle aspiration, endobronchial biopsy, and transbronchial biopsy (13). While endobronchial pathologies can be seen in most patients with sarcoidosis, normal endobronchial systems can be seen in 37\% (13). In our study, the most common pathology was mucosal hyperemia (42\%); the endobronchial system was normal in $28 \%$ of cases. In BAL in sarcoidosis, lymphocyte predominance (13) and elevated CD4/ CD8 are typically expected. Lymphocyte predominance was observed in most of our familial sarcoidosis patients undergoing BAL. Lymph node biopsy, mediastinoscopy, VATS, and lung biopsy are other invasive techniques used for tissue diagnosis $(13,19)$. In our study, most of the cases were diagnosed by mediastinoscopy. However, our study involves a 20-year period between 1996 and 2016. Most of the patients were diagnosed in the period before the use of endobronchial ultrasonography (EBUS) in our hospital. EBUS has recently entered into use in our hospital, and it has become a secondary diagnostic method in patients for whom diagnosis cannot be established through conventional bronchoscopy or primary diagnostic techniques. In this way, many patients can be diagnosed without the need for mediastinoscopy.

The limitations of the study include the retrospective nature of the study, the collection of data from patient files, and the lack of HLA typing and genetic analysis. However, the strength of the study is that it was performed in a hospital where the patients were followed up by experienced chest disease specialists in the outpatient sarcoidosis clinic; also, it is the first research study that has ever been conducted on familial sarcoidosis in Turkey.

\section{CONCLUSION}

In our series, the rate of familial sarcoidosis was found to be $4 \%$. Therefore, questioning sarcoidosis patients about the existence of another sarcoidosis case in the family or of a family member having complaints consistent with sarcoidosis can contribute to early diagnosis. The etiology of familial sarcoidosis and familial inheritance mechanisms is not exactly known. Further HLA typing studies and genetic analyses should be conducted on these patients. Our study is important because it reveals the presence of familial sarcoidosis in our country and provides a basis for further studies to investigate the genetic predisposition of sarcoidosis.

Ethics Committee Approval: Ethics committee approval was received for this study from the ethics committee of Süreyyapaşa Chest Diseases and Thoracic Surgery Training and Research Hospital.

Informed Consent: Due to the retrospective design of the study, informed consent was not taken.

Peer-review: Externally peer-reviewed.

Author Contributions: Concept - D.D., E.A.; Design - D.D., T.S.; Supervision D.D., T.S., E.A., A.H.; Resources - D.D., T.S., E.A., A.H.; Materials - D.D., L.S., O.A., 
S.G., M.Y., I.E., R.Y., S.B., M.K., A.H., E.A.; Data Collection and/or Processing - D.D., L.S., O.A., S.G., M.Y., I.E., R.Y., S.B., M.K., A.H.; Analysis and/or Interpretation D.D., T.S., E.A., S.G.; Literature Search - D.D., E.A.; Writing Manuscript - D.D.; Critical Review - D.D., T.S., E.A.; Other - D.D.

Conflict of Interest: No conflict of interest was declared by the authors.

Financial Disclosure: The authors declared that this study has received no financial support.

\section{REFERENCES}

1. Statement on sarcoidosis. Joint Statement of the American Thoracic Society (ATS), The European Respiratory Society (ERS) and The World Association of Sarcoidosis and Other Granulomatous Disorders (WASOG) adopted by the ERS Executive Committee, 1999. Am J Respir Care Med 1999; 160: 736-55.

2. Rybicki BA, Harrington D, Major M, Simoff M, Popovich J Jr, Maliarik M, et al. Heterogeneity of familial risk in sarcoidosis. Genet Epidemiol 1996; 13: 23-33. [CrossRef]

3. Fite E, Alsina JM, Anto JM, Morera J. Sarcoidosis: family contact study. Respiration 1998; 65: 34-9. [CrossRef]

4. Rybicki BA, Kirkey KL, Major M, Maliarik MJ, Popovich J Jr, Chase GA, et al. Familial risk ratio of sarcoidosis in Africa-American sibs and parents. Am J Epidemiol 2001; 153: 188-93. [CrossRef]

5. Martenstein $\mathrm{H}$. Knochverandungen bei Lupus pernio. Zentrabel Haut Geschtskrankh 1923; 7: 308

6. Martin WJ 2nd, lannuzzi MC, Gail DB, Peavy HH. Future directions in sarcoidosis research: summary of an NHLBI workıng group. Am J Respir Crit Care Med 2004; 170: 567-71. [CrossRef]

7. McGrath DS, Daniil Z, Foley P, du Bois JL, Lympany PA, Cullinan P, et al. Epidemiology of familial sarcoidosis in the UK. Thorax 2000; 55: 751-4. [CrossRef]

8. Musellim B, Kumbasar OO, Ongen G, Çetinkaya E, Turker H, Uzaslan H, et al. Epidemiological features of Turkish patients with sarcoidosis. Respir Med 2009; 103: 907-12. [CrossRef]
9. Aykan FS, Türktaş H, Köktürk N, Akten SY. Retrospective Evaluation of 100 Patients with Sarcoidosis in Gazi University, Turkey. Turk Thorac J 2014; 15: 155-61. [CrossRef]

10. Harrington DW, Major M, Rybicki B, Popovich J, Maliarik M, lannuzzi MC. Familial sarcoidosis: analysis of 91 families. Sarcoidosis 1994: 11: 240-3.

11. Pietinalho $A$, Ohmichi $M$, Hirasawa $M$, Hiraga $Y$, Löfroos A-B, Selroos O. Familial sarcoidosis in Finland and Hokkaido, Japan- a comparative study. Respir Med 1999; 93: 408-12. [CrossRef]

12. Rybicki BA, lannuzzi MC, Frederick MM, Thompson BW, Rossman MD, Bresnitz EA, et al. Familial aggregation of sarcoidosis. A case control etiologic study of sarcoidosis (ACCESS). Am J Respir Crit Care Med 2001; 164 2085-91. [CrossRef]

13. Kıter G, Müsellim B, Çetinkaya E, Türker H, Kunt Uzaslan E, Yentürk E, et al. Clinical presentations and diagnostic work-up in sarcoidosis: a series of Turkish cases. Tüberküloz ve Toraks Dergisi 2011; 59: 248-58. [CrossRef]

14. Luisetti M, Beretta A, Casali L. Genetic aspects in sarcoidosis. Eur Respir J 2000; 16: 768-80. [CrossRef]

15. Yavşan DM, Göktepe M, Koçak N, Dinç M, Uyanmış A, Uzun K. Olgu sunumu: Ailesel sarkoidoz. Genel Tıp Dergisi 2013; 23: 130-2.

16. Uyar M, Elbek O, Tükenmez E, Ekiz Ş, Uçak R, Dikensoy Ö. Familyal Sarkoidoz. Eurasian J Pulmonol 2006; 8: 174-8.

17. Brennan NJ, Crean P, Long JP, Fitzgerald MX. High prevelance of familial sarcoidosis in an Irish population. Thorax 1984: 39: 14-8. [CrossRef]

18. Baughman RP, Teirstein AS, Judson MA, Rossman MD, Yeager $\mathrm{H}$ Jr, Bresnitz EA, et al. Case Control Etiologic Study of Sarcoidosis (ACCESS) Research Group. Clinical characteristics of patients in a case control study of sarcoidosis. Am J Respir Crit Care Med 2001; 164: 1885-9. [CrossRef]

19. Baran A, Özşeker F, Günelioğlu D, Bilgin S, Arslan $S$, Uyanusta Ç, et al. Sarkoidoz: Yedi Yılık Deneyim. Turk Thorac J 2004; 5: 160-5.

20. İçten S, Altıntaş N, Helvacı A, Aslan E. Merkezimizdeki Sarkoidoz OlguIarının Klinik Özellikleri ve Değerlendirilmesi, 7 Yllık Tecrübemiz. Okmeydanı Tıp Dergisi 2013; 29: 67-71.

21. Ece T. Invasive diagnosis of sarcoidosis. Turkiye Klinikleri J Pulm Med-Special Topics 2009; 2: 68-7. 